\title{
Relieving hepatic steatosis: Another benefit of dipeptidyl peptidase-4 (DPP4) inhibitors
}

\author{
Zachary Braunstein, Jixin Zhong
}

Hepatic steatosis is strongly associated with type 2 diabetes (T2DM), both of which are common disorders resulting from obesity [1]. Compared to the general population, there is a higher risk for chronic liver disease and cirrhosis, arising from hepatic steatosis, in diabetic persons [2.3-fold increase of mortality in older onset (diagnosed after age 30) and 4.8-fold increase of mortality in younger onset (diagnosed before age 30)] [2]. Therefore, hepatic steatosis is a key issue in the treatment of T2DM. Furthermore in recent studies, dipeptidyl peptidase-4 (DPP4) inhibition has been suggested to ameliorate hepatic steatosis [3-5].

Oral delivery of glucose induces a greater insulin response than intravenous delivery, a phenomenon called "incretin effect". This effect is mediated by so called "incretin hormones", including glucagon-like peptide 1 (GLP-1) and gastric inhibitory polypeptide (GIP), two small peptides produced by enteroendocrine $\mathrm{L}$ cells and $\mathrm{K}$ cells, respectively [6]. One primary role of incretins is to promote postprandial insulin secretion. They increase insulin biosynthesis through a PDX-1dependent pathway [7]. These incretins can be rapidly inactivated by DPP4 [8]. DPP4 inhibitors are a novel class of oral anti-diabetic drugs with several available in the market for the treatment of diabetes: sitagliptin (Januvia, marketed by Merck \& Co., FDA approved 2006), vildagliptin (Galvus, marketed by Novartis, European Medicines Agency approved 2007), Saxagliptin (Onglyza,

Zachary Braunstein ${ }^{1}$, Jixin Zhong ${ }^{2}$

Affiliations: ${ }^{1 B}$ Boonshoft School of Medicine, Wright State University, Dayton, Ohio, USA; '2Department of Medicine, University of Maryland School of Medicine, Baltimore, Maryland, USA.

Corresponding Author: Jixin Zhong, MD, PhD, Department of Medicine University of Maryland School of Medicine 20 Penn St., S022; Baltimore, MD 21201 USA; Phone number: 410-706-3582; Fax: 410-706-3583; E-mail: jzhong@medicine.umaryland.edu

Received: 01 February 2015

Published: 15 July 2015 marketed by Bristol-Myers Squibb and AstraZeneca, FDA approved 2009), linagliptin (Tradjenta, marketed by Eli Lily Co and Boehringer Ingelheim), and alogliptin (Nesina, marketed by Takeda Pharmaceutical Co., FDA approved 2013).There are also two DPP4 inhibitors that were approved in Japan in 2012: anagliptin (trade name Suiny) and teneligliptin (trade name Tenelia). DPP4 inhibitors have shown mild effect on glycemia lowering, with a $0.4-0.8 \%$ lowering of HbA1c [9-11]. However, they are weight neutral, easy to use (oral delivery), and well-tolerated (especially with regards to hypoglycemia) and thus widely utilized in clinic. Both clinical trials and experimental evidence indicate $\mathrm{DPP}_{4}$ inhibitors are safe from a cardiovascular standpoint [12-15].

In a recent paper published in the June 2015 issue of Diabetes, DPP4 inhibition by MKo626, an analog of des-fluoro-sitagliptin (Merck Research Laboratories, West Point, PA), prevented western diet-induced hepatic steatosis and insulin resistance through hepatic lipid remodeling and modulation of hepatic mitochondrial function [3]. We showed that DPP4 inhibition improved liver insulin sensitivity and ameliorated hepatic diacylglycerol accumulation, independent of changes in body weight or adiposity. Triglyceride accumulation in the liver is a major cause of hepatic steatosis and hepatic triglyceride export, via very low density lipoprotein (VLDL), is an important mechanism utilized by the liver to eliminate excessive triglycerides [16]. Western diet resulted in a dramatic reduction in liver triglyceride secretion and MKo626 was shown to partially reverse this effect. VLDL export of triglyceride requires microsomal triglyceride transfer protein (MTTP) and Apolipoprotein B (apoB), both of which increased in MKo626-treated western diet-fed mice. We showed that DPP4 inhibition also reduced hepatic diacylglycerol and triglyceride accumulation by enhancing mitochondrial carbohydrate utilization. Hepatic mitochondrial function was significantly improved in MKo626-treated mice as evidenced by increased pyruvate dehydrogenase (PDH) activity and tricarboxylic acid (TCA) cycle flux. Western diet-induced reduction of sirtuin-1 (Sirt1), an important regulator of mitochondrial function [17], was completely prevented by DPP4 inhibition. Consistent with this, 
Sirt1-regulated genes (including PGC-1a, CPT-1, TFAM and PPAR- $\alpha$ ) increased in MKo626-treated mice. DPP4 inhibition also decreased incomplete palmitate oxidation, a marker of hepatic insulin resistance and mitochondrial dysfunction [18], in western diet-fed mice.

In summary, there are several recent studies suggesting a role of $\mathrm{DPP}_{4}$ inhibitors in improving diabetes-associated fatty liver disease. Both hepatic lipid remodeling and mitochondrial function modulation may perhaps be involved in this process. However, further studies are required to confirm the relieving effect of DPP4 on fatty liver disease. Effect of other DPP4 inhibitors need to be further examined. Although the improving effect of vildagliptin on hepatic steatosis has been observed in a human study with a total of 44 T2DM patients, this effect in humans needs to be confirmed in future studies with a larger sample size.

Keywords: Hepatic Steatosis, Dipeptidyl peptidase-4 inhibitors, DPP4

\section{How to cite this article}

Braunstein Z, Zhong J. Relieving hepatic steatosis: Another benefit of dipeptidyl peptidase-4 (DPP4) inhibitors. Int $\mathrm{J}$ Hepatobiliary Pancreat Dis 2015;5:67-69.

Article ID: 100036IJHPDZB2015

$* * * * * * * * *$

doi:10.5348/ijhpd-2015-36-ED-11

$* * * * * * * * *$

\section{Author Contributions}

Zachary Braunstein - Substantial contributions to conception and design, Acquisition of data, Analysis and interpretation of data, Drafting the article, Revising it critically for important intellectual content, Final approval of the version to be published

Jixin Zhong - Analysis and interpretation of data, Revising it critically for important intellectual content, Final approval of the version to be published

\section{Guarantor}

The corresponding author is the guarantor of submission.

\section{Conflict of Interest}

Authors declare no conflict of interest.

\section{Copyright}

(C) 2015 Zachary Braunstein. This article is distributed under the terms of Creative Commons Attribution
License which permits unrestricted use, distribution and reproduction in any medium provided the original author(s) and original publisher are properly credited. Please see the copyright policy on the journal website for more information.

\section{REFERENCES}

1. Roden M. Mechanisms of Disease: hepatic steatosis in type 2 diabetes--pathogenesis and clinical relevance. Nat Clin Pract Endocrinol Metab 2006 Jun;2(6):33548.

2. Moss SE, Klein R, Klein BE. Cause-specific mortality in a population-based study of diabetes. Am J Public Health 1991 Sep;81(9):1158-62.

3. Aroor AR, Habibi J, Ford DA, et al. Dipeptidyl peptidase-4 inhibition ameliorates Western dietinduced hepatic steatosis and insulin resistance through hepatic lipid remodeling and modulation of hepatic mitochondrial function. Diabetes 2015 Jun;64(6):1988-2001.

4. Ohyama T, Sato K, Yamazaki Y, et al. MK-0626, a selective DPP-4 inhibitor, attenuates hepatic steatosis in ob/ob mice. World J Gastroenterol 2014 Nov 21;20(43):16227-35.

5. Macauley M, Hollingsworth KG, Smith FE, et al. Effect of vildagliptin on hepatic steatosis. J Clin Endocrinol Metab 2015 Apr;100(4):1578-85.

6. Meier JJ, Gallwitz B, Nauck MA. Glucagon-like peptide 1 and gastric inhibitory polypeptide: potential applications in type 2 diabetes mellitus. BioDrugs 2003;17(2):93-102.

7. Zhong J, Rao X, Rajagopalan S. An emerging role of dipeptidyl peptidase 4 (DPP4) beyond glucose control: potential implications in cardiovascular disease. Atherosclerosis 2013 Feb;226(2):305-14.

8. Advani A, Bugyei-Twum A, Connelly KA. Cardiovascular effects of incretins in diabetes. Can J Diabetes 2013 Oct;37(5):309-14.

9. Zhong J, Maiseyeu A, Davis SN, Rajagopalan S. DPP4 in cardiometabolic disease: recent insights from the laboratory and clinical trials of DPP4 inhibition. Circ Res 2015 Apr 10;116(8):1491-504.

10. Karagiannis T, Paschos P, Paletas K, Matthews DR, Tsapas A. Dipeptidyl peptidase-4 inhibitors for treatment of type 2 diabetes mellitus in the clinical setting: systematic review and meta-analysis. BMJ 2012 Mar 12;344:e1369.

11. Park H, Park C, Kim Y, Rascati KL. Efficacy and safety of dipeptidyl peptidase-4 inhibitors in type 2 diabetes: meta-analysis. Ann Pharmacother 2012 Nov;46(11):1453-69.

12. Scirica BM, Bhatt DL, Braunwald E, et al. Saxagliptin and cardiovascular outcomes in patients with type 2 diabetes mellitus. N Engl J Med 2013 Oct 3;369(14):1317-26.

13. White WB, Cannon CP, Heller SR, et al. Alogliptin after acute coronary syndrome in patients with type 2 diabetes. N Engl J Med 2013 Oct 3;369(14):1327-35.

14. Mulvihill EE, Drucker DJ. Pharmacology, physiology, and mechanisms of action of dipeptidyl peptidase-4 inhibitors. Endocr Rev 2014 Dec;35(6):992-1019. 
15. Patil HR, Al Badarin FJ, Al Shami HA, et al. Metaanalysis of effect of dipeptidyl peptidase-4 inhibitors on cardiovascular risk in type 2 diabetes mellitus. Am J Cardiol 2012 Sep 15;110(6):826-33.

16. Kawano Y, Cohen DE. Mechanisms of hepatic triglyceride accumulation in non-alcoholic fatty liver disease. J Gastroenterol 2013 Apr;48(4):434-41.

17. Lagouge M, Argmann C, Gerhart-Hines $Z$, et al. Resveratrol improves mitochondrial function and protects against metabolic disease by activating SIRT 1 and PGC-1alpha. Cell 2006 Dec 15;127(6):1109-22.

18. Adams $\mathrm{SH}$, Hoppel $\mathrm{CL}$, Lok $\mathrm{KH}$, et al. Plasma acylcarnitine profiles suggest incomplete long-chain fatty acid beta-oxidation and altered tricarboxylic acid cycle activity in type 2 diabetic African-American women. J Nutr 2009 Jun;139(6):1073-81.
Access full text article on other devices

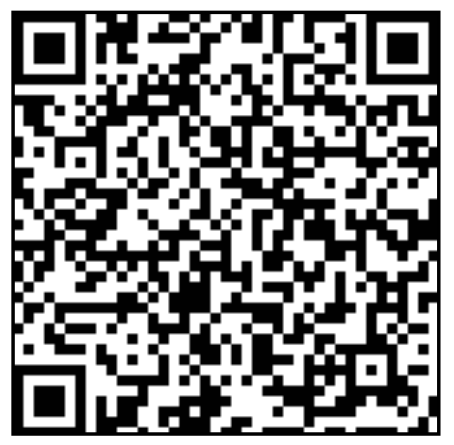

Access PDF of article on other devices

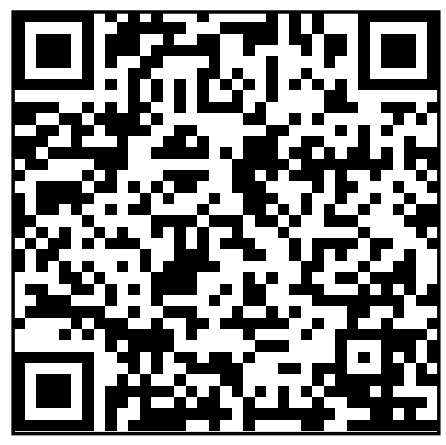

